\title{
THE CIDR1 $\alpha$-PfEMP1 SEQUENCE FROM INDONESIAN PLASMODIUM FALCIPARUM AND ITS POTENTIAL ASSOCIATION WITH THE CEREBRAL OUTCOME
}

\author{
Erma Sulistyaningsih ${ }^{1,2}$, Yunita Armiyanti ${ }^{1}$, Rosita Dewi ${ }^{2,3}$ \\ Correspondence: sulistyaningsih.fk@unej.ac.id \\ ${ }^{1}$ Parasitology Department, Faculty of Medicine, University of Jember, Jember, Indonesia \\ ${ }^{2}$ Center for Development of Advanced Science and Technology, University of Jember, Jember, Indonesia \\ ${ }^{3}$ Histology Department, Faculty of Medicine, University of Jember, Jember, Indonesia
}

Article History:

Received: October 24, 2020

Accepted: December 1, 2020

Published: Jasnuary 1, 2021

\section{Cite this as:}

Sulistyaningsih E, Armiyanti $Y$,

Dewi R. The cidrla-pfemp1

sequence from indonesian

plasmodium falciparum and its

potential association with the

cerebral outcome. Malang

Neurology Journal; 2021.7:34-

39.

http://dx.doi.org/10.21776/ub.mnj .2021 .007 .01 .8

\section{ABSTRACT}

Background: Plasmodium falciparum Erythrocyte Membrane Protein 1 (PfEMP1) is an important protein responsible for the pathogenesis of severe malaria, including cerebral malaria. The protein is highly diverse. The CIDR $1 \alpha$-PfEMP1 binds endothelial protein receptor (EPCR) and may associated with the brain swelling in childhood malaria.

Objective: To analyze the CIDR1 $\alpha$-PfEMP1 from Indonesian isolate and determine its association with cerebral malaria outcome.

Methods: Fifteen blood samples of clinically mild to severe malaria-patient were collected for DNA extraction. Malaria diagnosis was conducted microscopically by Giemsa-stained thin blood smear. The CIDR $1 \alpha$ domain was amplified by PCR using specific primer and PCR product was sequenced. The nucleotide sequences were analyzed by NCBI blast, DNASIS MAX 3 and translated into amino acid sequences using Expasy Translation Tool.

Results: One out of fifteen samples was severe malaria case and infected with P. falciparum, the rest were clinically mild to moderate malaria and infected with pure $P$. falciparum or mixed infection of $P$. falciparum and P. vivax. Amplification for CIDR1 $\alpha$ domain resulted a single band of +550 bp from a severe sample only. Sequencing of PCR product on both strands read 524 nucleotides and BLAST analysis confirmed as CIDR $1 \alpha$ sequence. Multiple alignment showed 74-78\% nucleotide sequence similarity with reference sequences, but amino acid sequences presented $23.5 \%$ homologous.

Conclusion: An identified CIDR1 $\alpha$ domain only from severe case implicating the potential association with the severe outcome including cerebral malaria, but the highly diverse of the domain needs further studies on the interaction with the pathological-causing receptor in the host.

Keywords: Cerebral outcome, CIDR1 $\alpha$, PfEMP1, Plasmodium falciparum

\section{Introduction}

Malaria is infectious disease caused by Plasmodium sp and transmitted by female Anopheles mosquito. It is responsible for 228 million cases with approximately 405.000 deaths annually.1 Plasmodium falciparum is the most prevalent malaria parasite in the world, ranging from $50 \%$ in SouthEast Asia Region, $71 \%$ in the Western Pacific Region to $99.7 \%$ in African Region. It is the most deadly Plasmodium, causing broad clinical symptoms from mild to severe cases even leading to death. ${ }^{1}$

The important pathology of $\mathrm{P}$. falciparum infection is cytoadherence and rosetting. ${ }^{2,3}$ There are several proteins involved in these two-central pathogenesis, one of the most important is P. falciparum Erythrocytes membrane Protein 1 (PfEMP1). ${ }^{4}$ PfEMP1 is a complex protein, contains a highly variable extra-cellular part and a relatively conserved intra-cellular part. The extra-cellular part consist of N-terminal segment (NTS) followed by 2-10 copies of two distinct binding domains: Duffy binding-like (DBL) and Cysteine-rich interdomain regions (CIDR). ${ }^{5}$
PfEMP1 is encoded by var gene family consisting of approximately 60 variable genes per haploid genome of the parasite. ${ }^{6}$ Var genes are highly variable in sequences but possess common structural features including conserved DBL and CIDR domains. The CIDR domain consists of semi-conserved stretches and is classified into three different types: $\square, \square, \square$ and $\delta .^{5}$ The CIDR $1 \alpha$ domain of several different PfEMP1 proteins was shown to bind CD36 and endothelial protein $\mathrm{C}$ receptor (EPCR). ${ }^{7,8}$ The expression of CIDR $1 \alpha$-PfEMP1and the EPCR-binding phenotype are associated with the severe childhood malaria. $^{8-10}$ Studies reported that EPCR-binding CIDR $1 \alpha$ domains are highly diverse, even in the EPCR-directly contact residue. In this report, we described the sequence characteristic of the CIDR $1 \alpha$ domain from Indonesian P. falciparum isolates and analyzed its potential association with malaria outcome. 


\section{Methods}

\section{Samples and Study Site}

Malaria patients were enrolled from the Primary Health Care in Jember district, East Java, Indonesia. Patients were informed and signed the informed consent before study. The study was received an ethical approval from the Ethical Committee of Faculty of Medicine University of Jember with the reference $\mathrm{Nr}$. 1114/H25.1.11/KE/2017. The inclusion criteria were infection with $\mathrm{P}$. falciparum either pure or mixed infection confirmed with microscopic examination of thin blood smears stained with Giemsa.

\section{DNA extraction and Amplification of CIDR-1 $\alpha$ domain}

Genomic DNA (gDNA) was isolated from blood samples of malaria patients by TIANamp Blood DNA kit (Tiangen Biotech) according to the manufacturer's instructions. The CIDR-1 $\alpha$ domain was amplified using specific primer according to previous study.(11) The primers were: CIDRF (5'- CGGGATCCAAATGGAAATGTTATTATG-3') and CIDR-R (5'-GGGGTACCTTGTAGTAATTTATCAATT3 ). The cycle conditions for the PCR were as follows: initial denaturation at $950 \mathrm{C}$ for $4 \mathrm{~min}$, followed by denaturation at $95 \mathrm{oC}$ for $45 \mathrm{sec}$, annealing at $46 \mathrm{oC}$ for 60 $\mathrm{sec}$ and extension at $72 \mathrm{oC}$ for $60 \mathrm{sec}$, for 35 cycles and final extension at $720 \mathrm{C}$ for $10 \mathrm{~min}$. The amplified fragments from PCR were electrophoresed in $1 \%$ agarose gel and visualized using UV light transilluminator.

\section{Sequencing of PCR products and Sequence Analysis}

PCR products were purified and directly sequenced using the ABI PRISM 3730 Version 3.1 sequencer (Applied Biosystems). The sample was sequenced on both strands, i.e., forward and reverse.

The nucleotide sequences derived from the P. falciparum field isolate were blasted to confirm its identity using Basic Local Alignment Search Tool (BLAST) in the National Center for Biotechnology Information (NCBI) (http://www.ncbi.nlm.nih.gov/Blast.cgi). The sequences were aligned and analyzed for sequence similarity by NCBI domain. The nucleotide sequences were translated into amino acid sequences using Expasy Translation Tool (http://www.expasy.ch/tool/dna.html). Percentage sequence similarity and phylogenetic tree building was carried out based on a Neighbour-Joining methods in DNASIS MAX 3.

\section{Results}

\section{Characteristic of samples}

As many as fifteen blood samples of malaria patients from Jember, East Java, Indonesia were enrolled in the study after written informed concern. Fourteen out of 15 patients $(93.3 \%)$ were male and the rest was female $(6.7 \%)$. One out of fifteen samples was severe malaria case and infected with P. falciparum, the rest were clinically mild to moderate malaria and infected either single infection of $\mathrm{P}$. falciparum or mixed infection of $\mathrm{P}$. falciparum and $\mathrm{P}$. vivax, as shown in Table 1.

Microscopic examination as a gold standard for malaria diagnosis confirmed 9 samples $(60 \%)$ pure of $\mathrm{P}$. falciparum infection, the rest patients $(40 \%)$ showed mixed infection of both $\mathrm{P}$. falciparum and $\mathrm{P}$. vivax. There were neither $\mathrm{P}$. malariae nor P. ovale infection. Clinical manifestation showed a wide range of symptom, where only a patient with $P$. falciparum infection showed a severe malaria with an anemia as a prominent symptom, the rest were either moderate or mild malaria. Based on WHO classification, malaria patient is categorized as having severe malaria when there are at least one symptom, either severe anemia, prostration, convulsion and respiratory distress, metabolic acidosis or cerebral malaria with impaired consciousness and coma.(12) In this study, the severe malaria patient had a symptom of severe anemia with the $\mathrm{Hb}<5 \mathrm{~g} / \mathrm{dL}$ and decreased of consciousness.

Table 1. Characteristic of Samples

\begin{tabular}{|c|c|c|c|c|}
\hline No & Sex & $\begin{array}{c}\text { Age } \\
\text { years }\end{array}$ & $\begin{array}{c}\text { Microscopical } \\
\text { Diagnosis }\end{array}$ & $\begin{array}{c}\text { Clinical } \\
\text { manifestation }\end{array}$ \\
\hline 1 & M & 35 & P. falciparum & $\begin{array}{l}\text { Moderate } \\
\text { malaria }\end{array}$ \\
\hline 2 & M & 28 & P. falciparum & Severe malaria \\
\hline 3 & M & 25 & P. falciparum & Mild malaria \\
\hline 4 & M & 32 & P. falciparum & Mild malaria \\
\hline 5 & M & 46 & $\begin{array}{c}P . \text { falciparum }+P . \\
\text { vivax }\end{array}$ & $\begin{array}{c}\text { Moderate } \\
\text { malaria }\end{array}$ \\
\hline 6 & M & 51 & $P$. falciparum & Mild malaria \\
\hline 7 & M & 39 & $\begin{array}{c}P . \text { falciparum }+P . \\
\text { vivax }\end{array}$ & Mild malaria \\
\hline 8 & M & 27 & $\begin{array}{c}\text { P. falciparum }+ \\
\text { P.vivax }\end{array}$ & $\begin{array}{l}\text { Moderate } \\
\text { malaria }\end{array}$ \\
\hline 9 & $\mathrm{~F}$ & 28 & $\begin{array}{l}P . \text { falciparum }+P . \\
\text { vivax }\end{array}$ & Mild malaria \\
\hline 10 & M & 30 & P. falciparum & Mild malaria \\
\hline 11 & M & 28 & P. falciparum $+P$. vivax & $\begin{array}{c}\text { Moderate } \\
\text { malaria }\end{array}$ \\
\hline 12 & M & 39 & P. falciparum $+P$. vivax & $\begin{array}{c}\text { Moderate } \\
\text { malaria }\end{array}$ \\
\hline 13 & M & 21 & P. falciparum & Mild malaria \\
\hline 14 & M & 21 & P. falciparum & Mild malaria \\
\hline 15 & M & 42 & P. falciparum & $\begin{array}{c}\text { Moderate } \\
\text { malaria }\end{array}$ \\
\hline
\end{tabular}

Amplification and Sequence Analysis of the CIDR-1 $\alpha$ Domain

The amplification of CIDR $1 \alpha$ sequence using specific primer resulted a single band of approximately $550 \mathrm{bp}$ in a severe malaria sample only, as shown in Fig. 1. The band is similar with the previous report on the CIDR domain that the CIDR sequence were approximately $600 \mathrm{bp}$ and $520 \mathrm{bp}$ from the cDNA amplification of iTG2.F6 strain and $510 \mathrm{bp}$ from the gDNA of K1 strain. ${ }^{11}$

The study also analyzed the CIDR $1 \alpha$ domain by sequencing. Sequencing from both strands resulted 524 nucleotides. BLAST-ing analysis showed that the resulted sequence had $74-78 \%$ sequence similarity with previous sequences of P. falciparum isolates in the GenBank. The phylogenetic tree analysis showed in Figure 2. The sequence had $82-84 \%$ identity with $\mathrm{P}$. falciparum reference sequences (LR129699.1 and LR131409.1) with the query coverage of $79-87 \%$. It also showed $78 \%$ identity and $99 \%$ query coverage with the KX154955.1, this is P. falciparum isolate 1994-3 and 1734-2 from Tanzania which is found from children with severe malaria, $74 \%$ identity and $98 \%$ query coverage with the CIDR $1 \alpha$ of 3D7 genome (LN999947.1 and XM_001349402.1), 77\% identity and $80 \%$ query coverage with P. falciparum from Papua New Guinea ((AF050740.1), and 73\% identity and 67\% query coverage with FCQ strain from Malayan Camp (AF008980.1). 


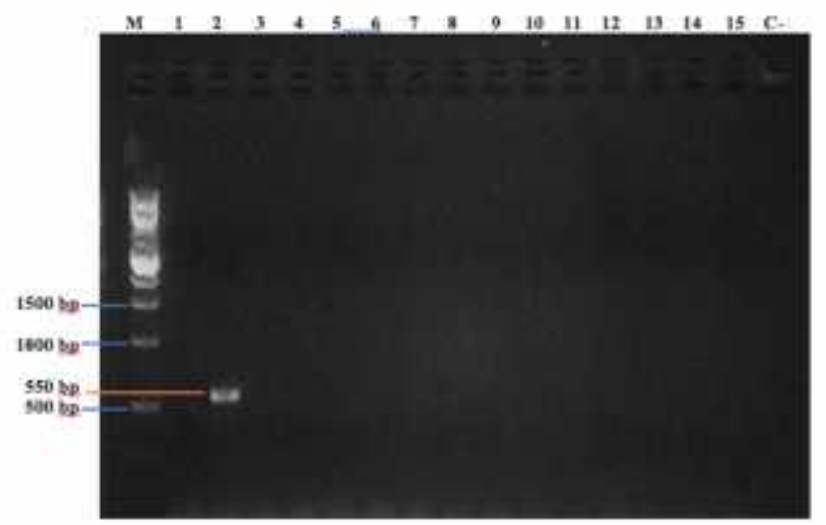

Figure 1. Amplification result of the CIDR $1 \alpha$ domain using specific primer. There are a single band of approximately $550 \mathrm{bp}$ band (orange line) from only one severe patient (lane 2: sample 2). M: $1 \mathrm{~kb}$ DNA marker; 1-15: Code number of samples; All samples except sample 2 showed negative result. C-: Negative control for PCR.

Translation of the nucleotide sequences into amino acid sequences using the Expasy Translation Tool resulted 174 amino acids. Analysis using Protein BLAST showed 98$100 \%$ coverage and $51-64 \%$ identity with several reference sequences (PF3D7, PFDG_01745_Dd2, PFFCH_05578, PFMALIP_05783, PFNF135_01540, PFRAJ116, PFTANZ_03634,PFTANZ_06110, PFUGT5.1). Multiple alignment using DNASIS MAX 3 resulted $23.5 \%$ homologous amino acid sequences as shown in Figure 3.

\section{Discussion}

Malaria is still major health problem in Indonesia, and mostly caused by P. falciparum which has a broad spectrum of clinical outcome from symptomatic, mild, moderate, severe until life threatening and causing death. One protein has a major role in the severe pathogenesis including cerebral malaria is PfEMP1. This study analysed the CIDR1 $\alpha$-PfEMP1 from Indonesian malaria patients and determined its association with severe malaria outcome, including cerebral malaria.

As many as 15 malaria patients were enrolled in the study, and the characteristic was shown in Table 1. Fourteen out of 15 patients were male and the rest one was female. This result is in accordance with the previous report that in some societies, men have a greater occupational risk of contracting malaria than women in mines, fields or forests at peak biting times of mosquitoes, or migrate to areas of high endemicity for work. $(13,14)$ Most of malaria patient in our study were migrant working from Java to Papua, Kalimantan and Nusa Tenggara, where the three areas were categorized as moderate to high endemic malaria areas in Indonesia.(15) They were infected in those migrant areas and returned as a malaria-infected person or referred from hospital to receive an appropriate treatment. Migrant workers as well as non-immune travellers are vulnerable to severe malaria, irrespective of the endemicity of the area where their infection was acquired. ${ }^{12}$ Malaria is still major health problem in Indonesia, and mostly caused by $P$. falciparum which has a broad spectrum of clinical outcome from symptomatic, mild, moderate, severe until life threatening and causing death. One protein has a major role in the severe pathogenesis including cerebral malaria is
PfEMP1. This study analysed the CIDR $1 \alpha$-PfEMP1 from Indonesian malaria patients and determined its association with severe malaria outcome, including cerebral malaria.

As many as 15 malaria patients were enrolled in the study, and the characteristic was shown in Table 1. Fourteen out of 15 patients were male and the rest one was female. This result is in accordance with the previous report that in some societies, men have a greater occupational risk of contracting malaria than women in mines, fields or forests at peak biting times of mosquitoes, or migrate to areas of high endemicity for work. ${ }^{13,14}$ Most of malaria patient in our study were migrant working from Java to Papua, Kalimantan and Nusa Tenggara, where the three areas were categorized as moderate to high endemic malaria areas in Indonesia. ${ }^{15}$ They were infected in those migrant areas and returned as a malaria-infected person or referred from hospital to receive an appropriate treatment. Migrant workers as well as non-immune travellers are vulnerable to severe malaria, irrespective of the endemicity of the area where their infection was acquired. ${ }^{12}$

Table 1 also showed that one out of fifteen samples was severe malaria case and infected with P. falciparum, the rest were clinically mild to moderate malaria and infected either single infection of $\mathrm{P}$. falciparum or mixed infection of $\mathrm{P}$. falciparum and P. vivax. As previously mentioned that $\mathrm{P}$. falciparum is the majority cause of malaria throughout the world, which resulted broad spectrum of clinically malaria outcome from asymptomatic, mild/uncomplicated malaria to severe malaria.

The severe malaria outcome in this study was severe anaemia with haemoglobin $<5 \mathrm{~g} / \mathrm{dl}$ and impaired of consciousness. Based on WHO epidemiological and research purposes, severe malaria is defined as one of more of the following symptoms, i.e., impaired consciousness, acidosis, hypoglycaemia, severe malarial anaemia, renal impairment, jaundice, pulmonary oedema, significant bleeding, shock, or hyperparasitaemia, occurring in the absence of an identified alternative cause and in the presence of P. falciparum in the blood. ${ }^{12}$

As previously reported that PfEMP1 plays a major role in the pathogenesis of severe malaria, we tried to identify the presence of the protein in the sample. Amplification of the CIDR1-PfEMP1 using CIDR specific primer resulted in a single band of approximately $550 \mathrm{bp}$ only from severe malaria sample, as presented in Figure 1. The band is similar with the CIDR domain previously reported, which were approximately $600 \mathrm{bp}, 520 \mathrm{bp}$ for CIDR of the cDNA amplification of iTG2.F6 strain, and $510 \mathrm{bp}$ from the gDNA of K1 strain. ${ }^{11}$

The PCR product of CIDR1—-PfEMP1 was further analysed by sequencing on both strands and resulted in 524 nucleotides. The sequence identification by blasting confirmed it as CIDR1-PfEMP1.

The sequence had $78 \%$ identity with the KX154955.1, this is P. falciparum isolate 1994-3 and 1734-2 from Tanzania which is found from children with severe malaria. The study also found that the expression of the CIDR1 which is bind to EPCR consistently found in both children suffering from severe malarial anemia or cerebral malaria. The result consistent with our finding that the only detected CIDR1- domain was from patient suffering from severe malaria with the symptom of anemia and impaired 


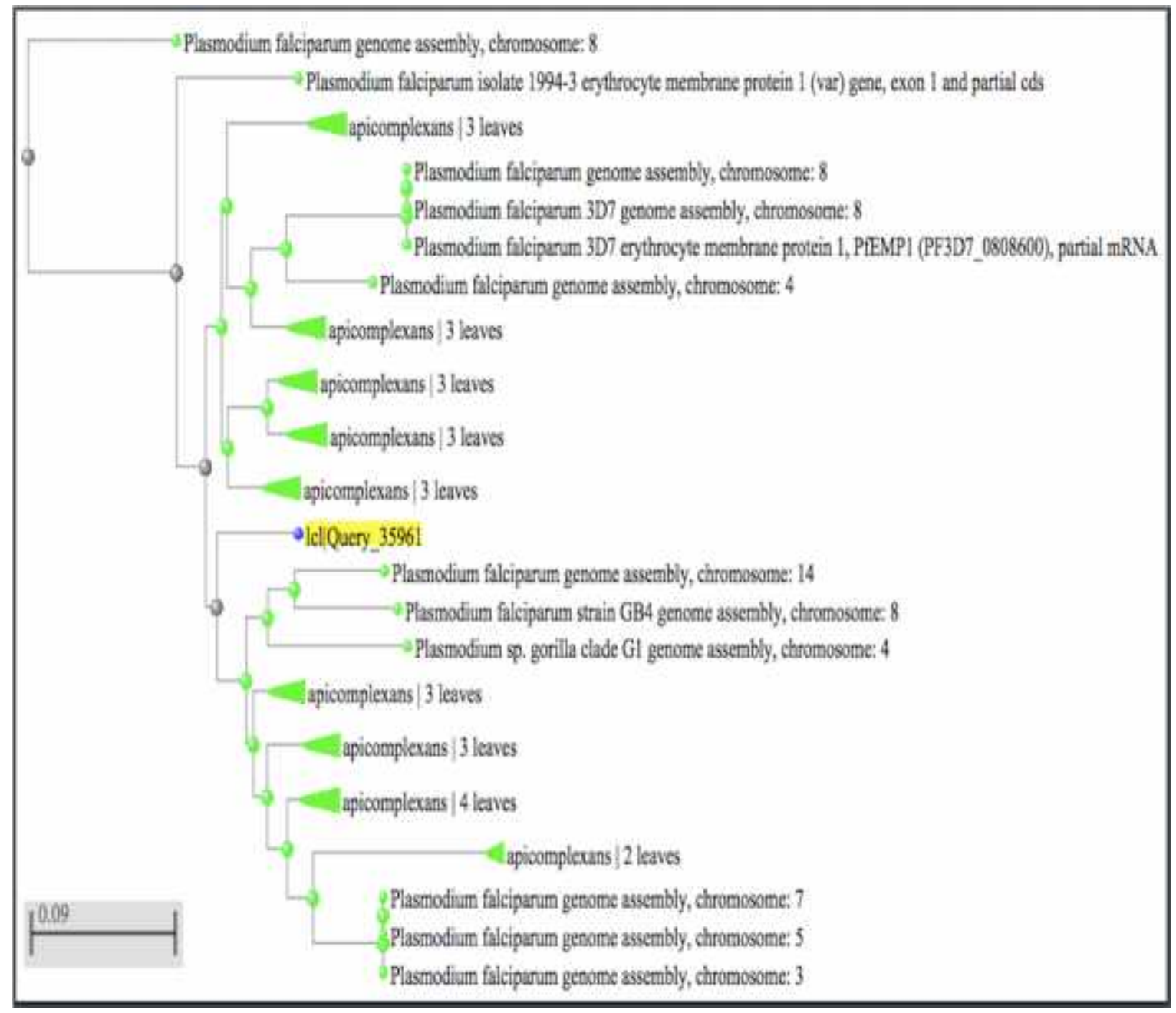

Figure 2. The phylogenetic tree of the CIDR-1 $\alpha$ from Indonesia isolate (yellow mark). The sequence had a very close identity with $P$. falciparum genome chromosome 14 (LR129699.1), P. falciparum GB4 chromosome 8 (LR131409.1). It also showed high identity with some $P$. falciparum genome chromosome 7, 5, and 3, and P. falciparum isolate 1994-3 and 1734-2 erythrocye membrane protein (var) gene (KX154955.1) from Tanzanian children with severe malaria, $P$. falciparum 3D7 genome (LN999947.1 and XM_001349402.1), $P$. falciparum from Papua New Guinea ((AF050740.1), and FCQ strain from Malayan Camp (AF008980.1).

consciousness. The slightly different is the age, where in previous study was in children but ours were adult patient. The result implicating the point that CIDR1-EPCR interaction is the key of severe malaria pathogenesis. ${ }^{8-10,16,17}$ The phylogenetic tree on Figure 2. demonstrated that the CIDR $1 \alpha$ domain from Indonesian isolate had a close relationship with the sequence of 3D7 strain, P. falciparum isolate 1994-3 and 1734-2 erythrocye membrane protein (var) gene from Tanzanian children, FCQ strain from Malayan Camp and Plasmodium falciparum from Papua New Guinea isolates. Although it is known that the var gene family-encoding PfEMP1 is highly diverse gene, it is likely that there is no clustering of the CIDR $1 \alpha$ sequences based on geographical origin. Furthermore, the N-terminal DBL-CIDR head structure of PfEMP1 has diverged molecular insight into its protein diversification, i.e. group A proteins diversified into those that bind EPCR (CIDR1 domain) and non-EPCR binders (CIDR / / domains) and group $\mathrm{B}$ and $\mathrm{C}$ encode for binding CD36 (CIDR 2-6 domains). ${ }^{9,10,18}$ Our CIDR1 -PfEMP1 sequence had high identity with the FCQ strain from Malayan Camp (AF008980.1), it is the P. falciparum FCG-27 clone which express the PfEMP1 region which is bind to CD36. The
CIDR1 is the domain mediating binding to CD36. Previous studies reported that there is a highly conserved shape of the domain which mediates adherence to CD36, particularly cysteine residues. Binding to CD36 is interesting as it is a feature of many parasite isolates. ${ }^{19}$ CD36 is a glycoprotein scavenger receptor found on the surface of various cells including platelets, macrophages, monocytes, leukocytes, dendritic cells, epithelial cells and microvascular endothelial cells. ${ }^{17}$ CD36 expression on cerebral endothelium of cerebral malaria patients was very little, but there was ubiquitously on lung, liver, kidney, skin and muscle vasculature. ${ }^{7}$ In the study we found that the severe patient showed an anaemia as the prominent symptom beside the impaired consciousness. The variability of the PfEMP1 is further confirmed by its homologous. The nucleotide sequences of CIDR1 PfEMP1 were translated into amino acid sequences using the Expasy Translation Tool and yielded 174 amino acids. Analysis using Protein BLAST showed 98-100\% coverage and $51-64 \%$ identity with several reference sequences (PF3D7, PFDG_01745_Dd2, PFFCH_05578, PFMALIP_05783, PFNF135_01540, PFRAJ116, PFTANZ_03634,PFTANZ_06110, PFUGT5.1). Figure 3 


\begin{tabular}{|c|c|c|c|c|c|c|c|}
\hline & & 670 & 680 & 690 & 70 & 70 & 70 \\
\hline CIDR1.Alpha & $--K V K C$ & RD & DSHKAI- - IIK & c166I & DTERT: & HitheV & VEItiss. \\
\hline PF3D7 & IVTVES & YD & 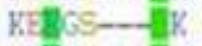 & 19: & MFEr & FPUHPEFUKS & 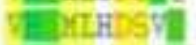 \\
\hline PFDG_01745_Dd2 & Iflysu & $X D$ & EHESP-DIK & Icteintin & okitra & 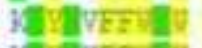 & YEMHESV \\
\hline PFFCH_05578 & ETUKC. & IVD & EADDKTYG & AIIFC LODG & NVITKD & 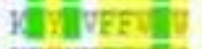 & BMIIDS \\
\hline PFMAIIP_05783 & IEEIRC & WD & EKATPS- - GK & 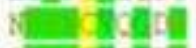 & GKYEKD & KPYYVERV 슬 & 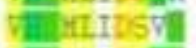 \\
\hline PFNF135_01540 & Inku & IVD & $-K D K P--{ }^{6} 6$ & 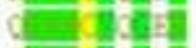 & KI & 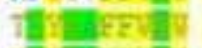 & 5EXIHDSA \\
\hline PFNF135_01541 & InKVEd & IDD & kirgP- & exces & KIfliku & Brivive & VEIHDSE \\
\hline PFAF135_02414 & IIXuEd & $Y D$ & DSETH:- & i & DTEROS & GEFvin & VYHMIHDSI \\
\hline PFRAJ11 $\overline{6}$ & IIINIT: & YD & 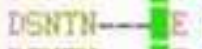 & d & KI thi & FFVXN & Villinge \\
\hline PFRAII16_2 & InKIE & YD & DSNTN-D-NE & C. & KI FKe & Ept proxu & ७YHATH HDSV \\
\hline PFIANZ_03634 & IBHE: & YD & KYBPS-- -90 & - cIIfin & BNVKCord- -8 & YGFIEU & Gining $\mathrm{K}$ \\
\hline PFTANZ_06110 & IVTH & & $-K O K L---116$ & Rerc & DT $\operatorname{Tog} \mathrm{A}-\mathrm{E}$ & EN JeFHe & 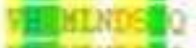 \\
\hline PFUGTS.1 & IREVII & & EIEPS-DAE & & & 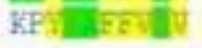 & К \\
\hline
\end{tabular}

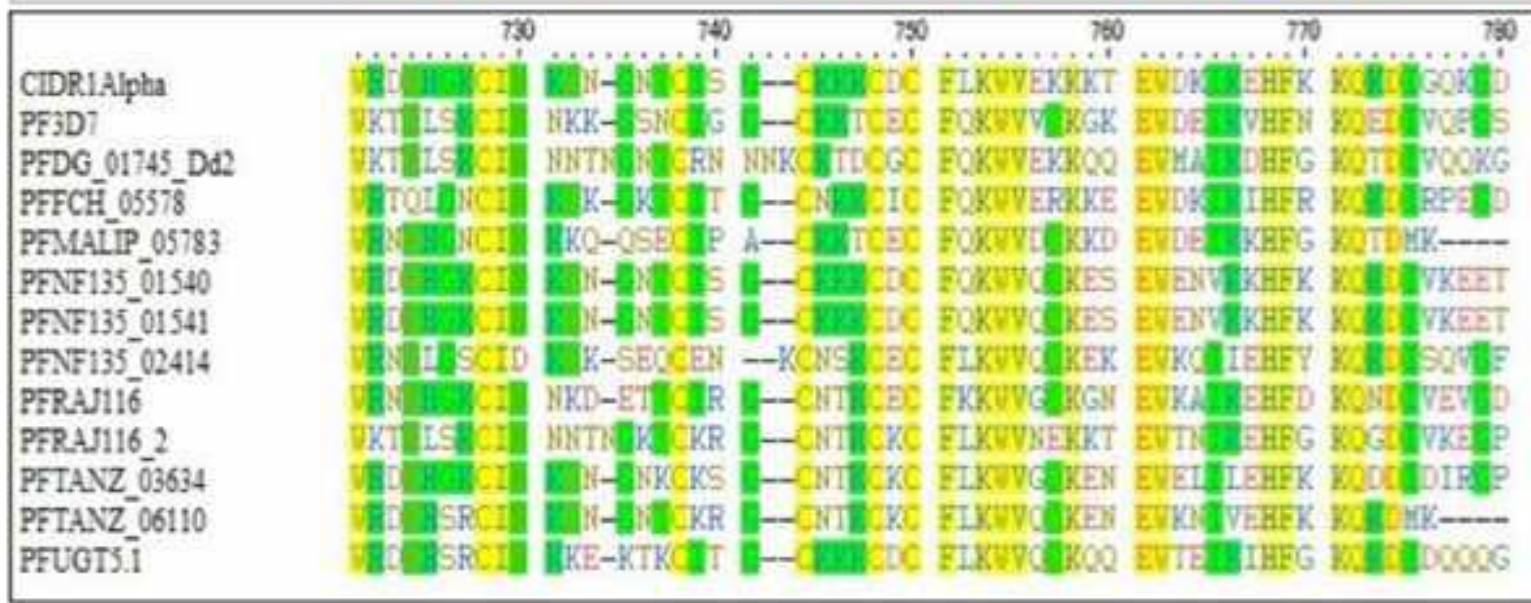

CIDRIAlphs

PF3D?

PFDG 01745 Dd2

PFFCH $0557 \overline{8}$

PFMALIP 05783

PFNF135 01540

PFNF135_01541

PFNF13502414

PFRAI116

PFRAJ116 2

PFTANZ 03634

PFTANZ 06110

PFUGTSi
790

800

610

-LGSVilitif

830

840

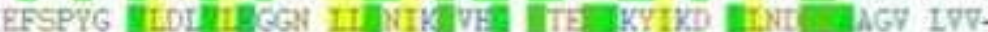

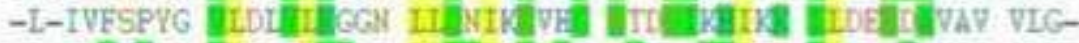

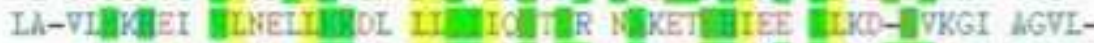

-.-IFIPSC AINVII

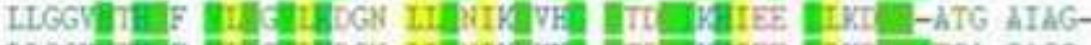

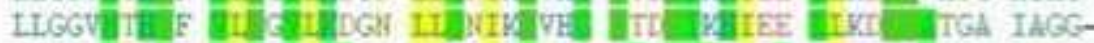

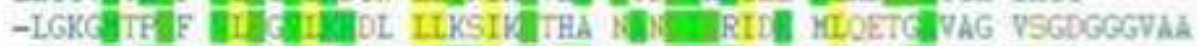

-LAER IIA I II

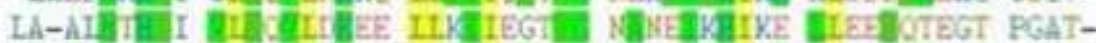

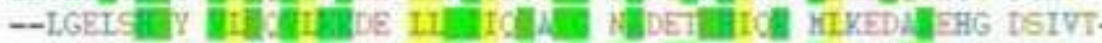

- - LIPPSY ALKF

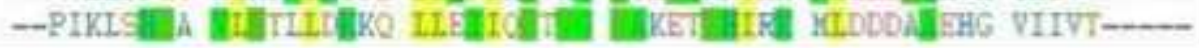

\section{CIDRLAlpha}

PFID?

PFDG_01745_DQ2

PFFCH 05578

PFMAIP 05783

PENF135 01540

PFNF13501541

PFNF13502414

PFRAJ116

PFRAI1162

PFTANZ 03634

PFTANZ 06110

PFUGTS.

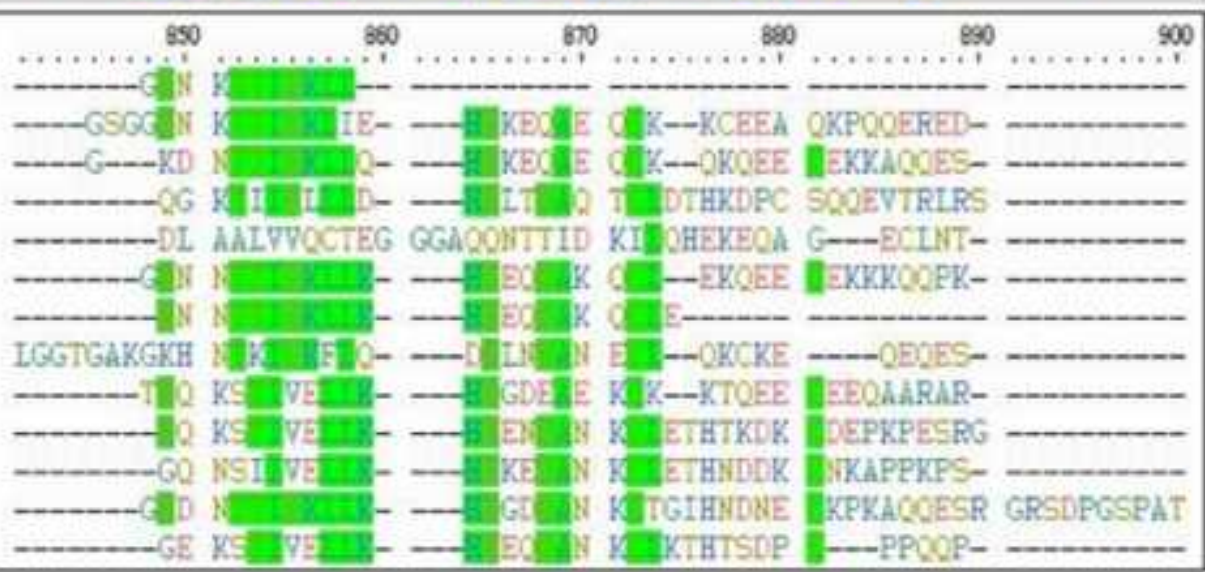

Figure 3. Multiple alignment of CIDR1 $\alpha$ domain of PfEMP1 from Indonesian isolate with several CIDR $1 \alpha$ reference sequences (PF3D7: P. falciparum 3D7; PFDG_01745_Dd2: P. falciparum Dd2 isolate; PFFCH: P. falciparum from Philippines; PFMALIP_05783: P. falciparum genome from Mali; PFNF135_01540: P. falciparum genome strain NF135, PFNF135_01541: P. falciparum genome strain NF135; PFNF135_02414: P. falciparum genome strain NF135; PFRAJ116: P. falciparum genome strain RAJ116: PFTANZ: P. falciparum genome from Tanzania; PFUGT5: P. falciparum genome strain UGT5. 
presented the CIDR1 -PfEMP1 amino acids multiple alignment using DNASIS MAX 3. It showed only $23.5 \%$ homologous amino acid sequences. This results further confirmed the variability of the CIDR1-PfEMP1.

\section{Conclusion}

We have reported the characteristic of CIDR $1 \alpha$ domain of PfEMP1 from Indonesian isolate which have 524 nucleotides in length and/or 174 amino acids sequences, and the closely relation with broad sequences from different origin. The fact that the domain only amplified from severe case implicating its role in clinically outcome. The interaction of CIDR $1 \alpha$ and EPCR which commonly found in human brain endothelial cells is suggested as the key mechanism of severe malaria outcome especially related to impairment consciousness, but the highly diverse of the domain needs further studies on the interaction with the receptors causing the pathomechanism in the host

\section{Acknowledgement}

The authors are thankful to the Head of CDAST-UNEJ Indonesia for the facilities and the Islamic Development Bank through four in one project for funding of the research.

\section{References}

1. WHO. World Malaria Report. 2019.

2. Miller LH, Baruch DI, Marsh K DO. The pathogenic basis of malaria. Nature [Internet]; 2002. 415(6872):673-9. Available from: https://pubmed.ncbi.nlm.nih.gov/11832955/

3. Chen Q, Heddini A, Barragan A, Fernandez V, Pearce SFA, Wahlgren M. The semiconserved head structure of Plasmodium falciparum erythrocyte membrane protein 1 mediates binding to multiple independent host receptors. J Exp Med; 2000. 192(1):1-9. DOI: 10.1084/jem.192.1.1

4. Magowan C, Wollish W, Anderson L, Leech J. Cytoadherence by Plasmodium Falciparum-infected erythrocytes is correlated with the expression of a family of variable proteins oninfected erythrocytes. J Exp Med; 1988. 168(4):1307-20. DOI: 10.1084/jem.168.4.1307

5. Smith JD, Subramanian G, Gamain B, Baruch DI ML. Classification of adhesive domains in the Plasmodium falciparum erythrocyte membrane protein 1 family. Mol Biochem Parasitol. 2000;110(2):293-310.

6. Gardner MJ(1), Hall N, Fung E, White O, Berriman M, Hyman RW, Carlton JM P, A, Nelson KE, Bowman S, Paulsen IT, James K, Eisen JA, Rutherford K S, SL, Craig A, Kyes S, Chan MS, Nene V, Shallom SJ, Suh B, Peterson J AS, Pertea M, Allen J, Selengut J, Haft D, Mather MW, Vaidya AB, Martin DM F, AH, Fraunholz MJ, Roos DS, Ralph SA, McFadden GI, Cummings LM SG, Mungall C, Venter JC, Carucci DJ, Hoffman SL, Newbold C, Davis RW FC, et al. Genome sequence of the human malaria parasite Plasmodium falciparum. Nature; 2002. 419(6906):498-511

7. Baruch DI, Ma XC, Singh HB, Bi X, Pasloske BL HR. Identification of a region of PfEMP1 that mediates adherence of Plasmodium falciparum infected erythrocytes to CD36: conserved function with variant sequence. Blood; 1997. 90(9):3766-75. DOI: https://doi.org/10.1182/blood.V90.9.3766

8. Jespersen JS, Wang CW, Mkumbaye SI, Minja DT, Petersen B, Turner L, et al. Plasmodium falciparum var genes expressed in children with severe malaria encode CIDR $\alpha 1$ domains. EMBO Mol Med; 2016. 8(8):839-50. DOI: 10.15252/emmm.201606188

9. Kessler A, Dankwa S, Bernabeu M, Harawa V, Danziger SA, Duffy F, et al. cerebral malaria; 2018. 22(5):601-14.

10. Lau CKY, Turner L, Jespersen JS, Lowe ED, Petersen B, Wang CW, et al. Structural conservation despite huge sequence diversity allows EPCR binding by the pfemp1 family implicated in severe childhood malaria. Cell Host Microbe [Internet]; 2015. 17(1):118-29. DOI: 1016/j.chom.2014.11.007

11. Degen R, Weiss N BH. Plasmodium falciparum: cloned and expressed CIDR domains of PfEMP1 bind to chondroitin sulfate A. Exp Parasitol; 2000. 95(2):113-21. DOI: 10.1006/expr.2000.4512

12. WHO. Severe Malaria. Trop Med Int Heal; 2014. 19 (Suppl I): 7-131.

13. WHO. Gender, health and malaria. Gend Heal; 2007

14. R R. Women and malaria--special risks and appropriate control strategy. Soc Sci Med; 1993. 37(4):473-80. DOI: https://doi.org/10.1016/02779536(93)90282-9

15. Elyazar IRF, Gething PW, Patil AP, Rogayah H, Kusriastuti R, Wismarini DM, et al. Plasmodium falciparum malaria endemicity in indonesia in 2010 . PLoS One; 2011;6(6).

DOI: https://doi.org/10.1371/journal.pone.0021315

16. Ochola LB, Siddondo BR, Ocholla H, Nkya S, Kimani EN, Williams TN, et al. Specific receptor usage in Plasmodium falciparum cytoadherence is associated with disease outcome. PLoS One; 2011. 6(3):1-9. DOI: https://doi.org/10.1371/journal.pone.0014741

17. Greenwalt DE, Lipsky RH, Ockenhouse CF, Ikeda H, Tandon NN JG. Membrane glycoprotein CD36: A review of its roles in adherence, signal transduction, and transfusion medicine. Blood; 1992. 80(5):110515. Avalaible form: https://pubmed.ncbi.nlm.nih.gov/1381234/

18. Hsieh FL, Turner L, Bolla JR, Robinson C V., Lavstsen T, Higgins MK. The structural basis for CD36 binding by the malaria parasite. Nat Commun [Internet]; 2016. 7(May):1-11. DOI: $10.1038 /$ ncomms 12837

19. Turner GDH, Van Chuong L, Mai NTH, Chau TTH, Phu NH, Bethell D, et al. Systemic endothelial activation occurs in both mild and severe malaria: Correlating dermal microvascular endothelial cell phenotype and soluble cell adhesion molecules with disease severity. Am J Pathol; 1998. 152(6):1477-87. Avalaible form: https://www.ncbi.nlm.nih.gov/pmc/articles/PMC1858 439/ 